\title{
Degradation of connexins and gap junctions
}

\author{
Matthias M. Falk ${ }^{1}$, Rachael M. Kells ${ }^{1}$, and Viviana M. Berthoud ${ }^{2}$ \\ ${ }^{1}$ Department of Biological Sciences, Lehigh University, 111 Research Drive, lacocca Hall, D-218, \\ Bethlehem, PA 18015, USA \\ ${ }^{2}$ Department of Pediatrics, University of Chicago, 900 East $57^{\text {th }}$ St., KCBD, room 5150 , Chicago, \\ IL 60637, USA
}

\begin{abstract}
Connexin proteins are short-lived within the cell, whether present in the secretory pathway or in gap junction plaques. Their levels can be modulated by their rate of degradation. Connexins, at different stages of assembly, are degraded through the proteasomal, endo-/lysosomal, and phago-/ lysosomal pathways. In this review, we summarize the current knowledge about connexin and gap junction degradation including the signals and protein-protein interactions that participate in their targeting for degradation.
\end{abstract}

\section{Keywords}

Autophagosome; connexin; gap junction; lysosome; proteasome; ubiquitin

\section{Introduction}

Connexins have an unexpected short half-life of only 1-5 hours even when their half-lives have been determined in tissues [1-5]. It is still puzzling that connexins, either unassembled or assembled into connexons (hemichannels) and especially when assembled and localized in gap junction plaques have - and apparently need - such a fast turnover. The degradation of connexins, connexons, and gap junctions, and alterations of their turnover accompany various physiological and pathological conditions (e.g., cell migration, mitosis, ischemia, etc.). This was discussed at one of the roundtables (themed "Internalization and degradation pathways of connexins and gap junctions") that were entertained at the 2013 International Gap Junction Conference (Charleston, SC, http://academicdepartments.musc.edu/igjc2013) and chaired by the senior authors of this article. Discussed topics, emerging concepts and hypotheses, and other relevant issues related to the turnover of connexins and gap junctions are summarized here.

() 2014 Federation of European Biochemical Societies. Published by Elsevier B.V. All rights reserved.

Please address correspondence to: mmf4@ lehigh.edu (Tel: 610-758-5896) or vberthou@ peds.bsd.uchicago.edu (Tel: 773-834-2115).

Publisher's Disclaimer: This is a PDF file of an unedited manuscript that has been accepted for publication. As a service to our customers we are providing this early version of the manuscript. The manuscript will undergo copyediting, typesetting, and review of the resulting proof before it is published in its final citable form. Please note that during the production process errors may be discovered which could affect the content, and all legal disclaimers that apply to the journal pertain. 
Gap junction plaques are internalized from the plasma membrane as vesicle-like doublemembrane structures termed annular gap junctions. The first electron microscopy images of these structures were published by Bjorkman from granulosa cells of the ovarian follicle [6]. Numerous other ultrastructural studies have shown the presence of annular gap junctions in several cell types and differentiating tissues [7-12]. A few ultrastructural studies reported annular gap junctions enclosed within double-membrane structures, which would be consistent with autophagic degradation of endocytosed gap junctions [9,13,14]. Liveimaging studies have also shown gap junction internalization [15-18]. Their internalization as double-membrane structures is in agreement with studies reporting that docked hemichannels (or connexons) in gap junction plaques appear inseparable under physiological conditions $[19,20]$. This internalization occurs through a combined endo/ exocytic process [21], because one of the cells acts as a receiver and the other acts as a donor (Figure 1).

Studies of wild type and mutant connexins have addressed their subcellular localization, channel function, internalization and/or turnover in transfected cells. The turnover of connexins is determined by the rates of synthesis and degradation, which occurs through the proteasomal and the lysosomal pathways. Several reviews on different aspects of connexin and gap junction degradation have been recently published [22-26].

This review will focus on the roles of these pathways on degradation of connexins within the secretory pathway vs. those in gap junction plaques, and the signals and protein-protein interactions that participate in targeting connexins for degradation through the proteasomal vs. the lysosomal pathways. First, we will briefly describe the different pathways and then describe the role of these pathways in the degradation of connexins and gap junctions localized in different cellular compartments.

\section{Proteasomal and lysosomal degradation pathways}

\subsection{The $26 \mathrm{~S}$ proteasome}

The 26S proteasome is a protein complex formed by a barrel-shaped $20 \mathrm{~S}$ core particle, which contains the proteolytic activity, and two 19S regulatory particles, one on each side of the core particle. The regulatory particle is composed of a ring-shaped base made of six ATPases and a lid [27]. Several proteasome inhibitors have been used to study the function of the proteasome including ALLN (N-Acetyl-L-leucyl-L-leucyl-L-norleucinal), lactacystin, $\mathrm{ZL}_{3} \mathrm{VS}$ (carboxybenzyl-leucyl-leucyl-leucine vinyl sulfone), epoxomicin and bortezomib $[28,29]$.

Degradation of cellular proteins by the proteasome can be ubiquitin-dependent or ubiquitinindependent. Modification of proteins by ubiquitin, a three-step process, results from the activity of an ubiquitin-activating enzyme (E1, the rate-limiting step), an ubiquitinconjugating enzyme (E2) and an ubiquitin-protein ligase (E3). This modification can be attached to the protein as one (mono) or several (multiple mono) single ubiquitin molecules, or as multimers of ubiquitin (poly-ubiquitin chain). Although ubiquitin lysine48-based chains have been associated with targeting proteins for proteasomal degradation, more recent studies suggest that these poly-ubiquitin chains can be formed by linkage of ubiquitin 
molecules between one of the six other lysines available for conjugation. Although it was initially thought that ubiquitination occurred only on lysine residues of the target protein, ubiquitination has been found in threonines, serines or cysteines and the amino group of the $\mathrm{N}$-terminal residue of the protein targeted for proteasomal degradation (reviewed in [30]). It has been hypothesized that the variety of proteasome-targeting ubiquitin motifs may determine the degradation rate of the target protein.

\subsection{Lysosomal degradation pathways}

Cells have evolved two degradation pathways that depend on the activities of lysosomal enzymes, endo-/lysosomal and phago-/lysosomal (termed macroautophagy, or simply, autophagy). The endo-/lysosomal pathway is designed for the uptake of extracellular nutrients and factors via the formation and internalization of vesicles from the plasma membrane. These vesicles then fuse with endosomes and lysosomes to degrade the cargo.

Macroautophagy is a lysosomal degradation pathway essential for cell survival that is activated by nutrient depletion. It is responsible for the degradation of cytoplasmic structures such as non-functional organelles, protein aggregates, and invading pathogens [31-34]. During autophagy, materials targeted for degradation are first sequestered by an isolation membrane (phagophore) forming a double-membrane vesicle (autophagosome), which then fuses with a lysosome where the cargo is degraded.

Because lysosomes are involved in both the endo-/lysosomal and auto-/phagosomal degradation pathways, the manipulation of specific components allows these pathways to be distinguished. The identification of autophagy-related genes and experimental manipulation of their levels have allowed evaluation of the contribution of autophagy to connexin/gap junction degradation. The microtubule-associated protein 1 light chain 3 (LC3) is considered the most specific autophagosomal marker [35]. LC3 is proteolytically processed shortly after translation and converted into LC3-I. LC3-I is converted to LC3-II after being recruited to developing phagophores and covalently conjugated to phosphatidyl-ethanolamine of the phagophore membrane. LC3-II remains on autophagosomes for most of their lifetime [35,36]. Other autophagosome-related genes include Atg5, Atg6 (Beclin) and Atg7.

\section{Signals involved in degradation of connexins}

Several modifications including phosphorylation, ubiquitination, SUMOylation, methylation, acetylation, nitrosylation, and glutamate $\gamma$-carboxylation have been found in connexins (reviewed recently in [37,38]). Of these phosphorylation and ubiquitination are known to function in protein degradation, and evidence that phosphorylation and ubiquitination also plays a role in the internalization of gap junction plaques and degradation of connexins has been obtained. The role of phosphorylation in internalization and degradation of gap junctions has been reviewed [39].

\subsection{Ubiquitination}

Cx43 and avian Cx45.6 are polyubiquitinated [40,41]. In NRK cells and TPA-treated rat liver epithelial IAR20 cells, Cx43 is multiply mono-ubiquitinated [42,43]. Several E3 ubiquitin ligases are involved in ubiquitination of connexins. Nedd4, Smurf2 and TRIM21 
are among the E3 ubiquitin ligases that interact with Cx43 [44-46]. All of them are associated with gap junction plaques (Figure 2). Ubiquitination of connexin at gap junction plaques appears to have a role in endocytosis and/or intracellular vesicle trafficking [42,47]. An interaction of E3 ubiquitin ligases with connexins that are rapidly degraded by endoplasmic reticulum-associated degradation or connexins in their transit to the plasma membrane may not be revealed by immunofluorescence, because the connexins are not concentrated in a particular area (as they are in gap junction plaques).

Nedd4 interacts via its WW domains with the carboxyl-terminus of $\mathrm{Cx} 43$ and ubiquitinates $\mathrm{Cx} 43$ in gap junctions $[42,46]$. It has been proposed that the resulting ubiquitinated $\mathrm{Cx} 43$ recruits Eps15 (a member of the clathrin-coat-associated sorting proteins (CLASPs) (reviewed in [48]) to gap junction plaques and mediates their internalization [42]. CLASPs encode conserved peptide sequences that contact ubiquitin-moieties across their surface (termed ubiquitin interacting motifs [UIMs]) and thus ensure ubiquitin signal-specificity. Interestingly, alternative CLASPs such as Eps15/Eps15R and Epsin1/2 may replace the canonical CLASP, AP-2, allowing clathrin-mediated endocytosis to occur independent of AP-2.

The Nedd4-interacting protein 2 (NDFIP2) is a short-lived protein that is degraded in the lysosome. siRNA silencing of NDFIP2 decreased the number of gap junction plaques associated with a small increase in Cx43 half-life, whereas overexpression of NDFIP2 increased the number and size of gap junction plaques and decreased the half-life of $\mathrm{Cx} 43$ [49]. Thus, it is possible that Nedd4-interacting proteins like NDFIP2 may regulate internalization of Nedd4-ubiquitinated $\mathrm{Cx} 43$ (and other connexins) from the plasma membrane.

Smurf2 modulates Cx43 endocytosis and degradation [45]. Treatment of IAR20 cells with the tumor promoter, 12-O-tetradecanoylphorbol 13-acetate (TPA), a protein kinase C activator, promotes $\mathrm{Cx} 43$ phosphorylation and ubiquitination, recruitment of Smurf2 to gap junction plaques and increases interaction between these proteins [43,45,50,51]. Treatment with a siRNA against Smurf2 leads to an increase in the size of gap junction plaques and in gap junction intercellular communication, and to prevention of the TPA-induced decrease in Cx43 at gap junctions [45]. The ubiquitin-binding proteins, Hrs (hepatocyte growth factorregulated tyrosine kinase substrate) and Tsg101 (tumor susceptibility gene 101), components of the endosomal sorting complex required for transport (ESCRT) have been identified as important for targeting of annular gap junction-endosome intermediates for lysosomal fusion and degradation [47] (Figure 2).

Proteomic analyses have identified lysyl residues modified by ubiquitin in several connexins. Mass spectrometric analyses of endoproteinase Lys-C/trypsin-digested HEK293T cell homogenates immunoprecipitated with anti-di-glycine-lysine antibodies show the presence of a di-glycine motif attached to lysines 9 and 303, suggesting that Cx 43 is ubiquitinated at these amino acid residues in these cells [52]. Using a similar strategy in mouse tissues, this di-glycine-lysine motif has been found in several lysyl residues from different connexins [53]. Interestingly, 12 of the 23 lysines from mouse $\mathrm{Cx} 43$, predicted to localize in the cytoplasm, have this modification [53]. However, ubiquitination at these sites 
needs to be experimentally validated, since some cautionary statements about the interpretation of mass spectrometry results have been made [30].

\subsection{Interaction with components of the clathrin-mediated endocytic machinery}

Internalization of gap junctions occurs preferentially into one of two coupled cells [3,17] suggesting the presence of markers that determine the sidedness of the internalization. This directionality may be aided by several proteins. Several components of the clathrin-mediated endocytosis machinery (e.g., clathrin, the clathrin-adaptors AP-2 and Dab2, the GTPase dynamin2), the retrograde actin motor myosin VI, and filamentous actin have been found in close-association with annular gap junctions [8,17,54-58] (Figure 2). Wayakanon et al., in analyzing Cx43 C-terminal deletion mutants obtained evidence that a region including the clathrin/AP-2 binding sites may be important in determining the directionality of internalization [59].

Two of the three canonical tyrosine-based AP-2 binding sites (sites S2 and S3) of the YXXФ type (where X stands for any amino acid and $\Phi$ is a hydrophobic amino acid with a bulky side chain) present in the C-terminus of $\mathrm{Cx} 43$ cooperate to mediate clathrin-mediated gap junction endocytosis [15]. Based on the limited availability of phosphatidylinositol 4,5bisphosphate $\left(\mathrm{PIP}_{2}\right)$ in gap junction plaques, a signaling lipid required for AP-2 binding and successful clathrin-mediated endocytosis [60,61], it is tempting to speculate that cooperation between the tyrosine-based AP-2 binding sites decreases the levels of $\mathrm{PIP}_{2}$ required for gap junction endocytosis. Whether these AP-2 binding sites play a role in constitutive and acutely induced gap junction endocytosis, as occurs for example in G-protein coupled receptor endocytosis [62] remains to be determined.

\subsection{Interaction with ZO-1}

Disaggregation of ventricular muscle leads to internalization of gap junctions [10] and causes an increase in the amount of the scaffolding protein, zonula occudens-1 (ZO-1) associated with Cx43 [63]. In vascular endothelial cells treated with thrombin or endothelin-1 and in Cx43-GFP transfected 42GPA9 Sertoli cells treated with lindane (a carcinogenic pesticide), ZO-1 is displaced from gap junction plaques on the side of plaque invagination $[64,65]$. These results imply that the increased $\mathrm{Cx} 43 / \mathrm{ZO}-1$ interaction occurs in the donor cell, and that there should be a decrease in the Cx43/ZO-1 interaction in the receiver cell. It remains to be determined whether the interaction of ZO-1 with actin plays a role in this process.

\subsection{Interaction with p62}

Sequestosome-1 (also known as p62) is a bifunctional protein that binds LC3 and ubiquitinated proteins and serves as a cargo receptor to deliver polyubiquitinated (lysine63linked) and potentially also monoubiquitinated oligomeric protein complexes to the autophagic degradation pathway [31,66-68]. Since connexins are modified by ubiquitin, their interaction with p62 is likely to target them for autophagic degradation (Figure 2). 


\section{Degradation of connexins/connexons in their transit to the plasma membrane}

\subsection{Proteasomal pathway}

The participation of the proteasome in connexin degradation was first reported for $\mathrm{Cx} 43$ [40]. Degradation of $\mathrm{Cx} 43$ in CHO cells containing a temperature sensitive mutant E1 was impaired at the restrictive temperature, and ubiquitinated proteins were detected in $\mathrm{Cx} 43$ immunoprecipitates from normal $\mathrm{CHO}$ cells re-precipitated with anti-ubiquitin antibodies [40]. Treatment of different $\mathrm{Cx} 43$-expressing cell lines with proteasomal inhibitors increases Cx43 levels and decreases its rate of degradation [40,69-72].

Both wild type $\mathrm{Cx} 43$ and $\mathrm{Cx} 32$ undergo endoplasmic reticulum associated proteasomemediated degradation (ERAD) [73] during or after protein biosynthesis. In several cell types that endogenously express $\mathrm{Cx} 43$ or $\mathrm{Cx} 32$, degradation of newly synthesized connexins was inhibited by ALLN (a proteasomal inhibitor) to a similar extent in the presence or absence of brefeldin A [73]. Proteasomal degradation of connexins retained in the endoplasmic reticulum requires their dislocation from this subcellular compartment into the cytosol. Several cytosolic stresses including changes in redox state and thermal stress can modulate connexin dislocation and endoplasmic reticulum-associated proteasomal degradation [71,74]. It has been estimated that a significant proportion ( $240 \%$ ) of newly synthesized wild type Cx32 and Cx43 may undergo endoplasmic reticulum-associated degradation [74], an unusually high rate from a metabolic point of view. It is not clear yet why connexin protein biosynthesis, translocation into the endoplasmic reticulum-membrane, and/or connexon-oligomerization may occur at such an inefficient rate, requiring degradation of almost one-half of newly synthesized $\mathrm{Cx}$ polypeptides.

CIP75 interacts with Cx43 and stimulates its degradation [75-77]. This protein (which is $100 \%$ identical in sequence to the mouse UBIN protein $[25,78]$ ) contains an ubiquitin-like (UBL) and ubiquitin-associated (UBA) domain that interacts with a region in the carboxyl terminus of $\mathrm{Cx} 43$ [75]. Although CIP75 interacts with ubiquitinated proteins and endoplasmic reticulum-localized $\mathrm{Cx} 43$ (Cx43-HKKSL, a genetically engineered $\mathrm{Cx} 43$ fusion protein encoding an HKKSL-endoplasmic reticulum retention signal [79]), the $\mathrm{Cx} 43$ HKKSL that co-precipitates with CIP75 is not ubiquitinated in lactacystin-treated cells expressing HA-tagged ubiquitin [77]. Co-immunoprecipitation experiments suggest that Cx43-HKKSL is in a complex with CIP75 and the proteasome subunits of the regulatory particle, Rpn1 and Rpn10. Treatment with DTT and bortezomib (which would lead to accumulation of dislocated Cx43-HKKSL in the cytosol) increased the amount of CIP75 and Rpn1 interacting with Cx43-HKKSL [76]. Newly published findings suggest that CIP75 plays a role in dislocating $\mathrm{Cx} 43$ from the endoplasmic reticulum and that it acts as an adaptor mediating the interaction of $\mathrm{Cx} 43$ with the proteasome [76].

\subsection{Lysosomal pathway}

Cx43 accumulates in lysosomes in Cx43-infected MDA-MB-231 cells (a human breast tumor cell line that is communication-deficient even after infection). Since treatment with BFA for 6 hours did not affect the lysosomal localization of Cx43 and inhibition of protein 
synthesis decreased the intensity of Cx43 immuno-reactivity, Qin et al. proposed that Cx43 could be targeted to the lysosome from an early secretory compartment [72]. A similar mechanism may be responsible for the accumulation of $\mathrm{Cx} 43$ in a lysosomal compartment in bovine aortic endothelial cells treated with TGF- $\beta 1$ [80].

\section{Degradation of gap junctions}

\subsection{Proteasomal pathway}

In some cell types, treatment with proteasomal inhibitors leads to an increase in Cx43 immuno-reactive gap junction plaques [1,71], and can also prevent (at least in part) the brefeldin A-induced decrease in immune-reactive $\mathrm{Cx} 43$ at gap junction plaques [70,72]. Yet, the proteasome inhibition-induced increase in $\mathrm{Cx} 43$ immuno-reactivity at gap junction plaques implicates that the proteasome is somehow involved in the degradation of gap junctional plaques. A high proportion of $\mathrm{Cx} 43$ gap junctional plaques in $\mathrm{BICR} / \mathrm{M} 1 \mathrm{R}_{\mathrm{k}}$ cells also bind anti-ubiquitin antibodies [81], however the ubiquitin addition could either signal proteasomal, or lysosomal degradation depending on its type. No ubiquitin type was specified. Most likely, the role of the proteasome in degradation of gap junction plaques is indirect; a conclusion that is supported by the highly oligomeric organization of gap junctions, and the proteasome being designed to degrade single unfolded polypeptides that need to be "spooled" into the central proteasome core (see section 2.1.). Several mechanisms have been proposed to explain its participation. 1) A short-lived protein may be required for targeting correctly folded connexins for proteasomal degradation [71]. 2) The proteasome regulates internalization of gap junctions by modulating the interaction of $\mathrm{Cx} 43$ with $\mathrm{ZO}-1$ [82]. 3) Treatment with proteasome inhibitors leads to an increase in the activity of the Akt protein kinase, which in turn, phosphorylates $\mathrm{Cx} 43$ leading to increased stability of the protein at gap junction plaques without requiring ubiquitination of $\mathrm{Cx} 43$ [83]. Mounting evidence now strongly suggests that the role of ubiquitination of connexins at gap junction plaques plays a critical role in the internalization of gap junctions [42,47] (Figure 2).

\subsection{Endo-/lysosomal pathway}

Membrane vesicles containing intact endocytosed gap junctions, or gap junctions apparently in the process of degradation have been observed in several ultrastructural studies $[7,57,84$ $86]$, suggesting that annular gap junctions may fuse with lysosomes $[57,84,86]$. These vesicular structures suggest involvement of the endo-/lysosomal pathway in the degradation of annular gap junctions.

Implicit in the degradation of annular gap junctions through the endo-/lysosomal pathway is the fusion of a double-membrane vesicle containing densely packed gap junction channels with a single-membrane organelle. The mechanism by which this occurs is unclear. It has been suggested that the inner membrane of the annular gap junction splits from the outer membrane, generating a single-membrane cytoplasmic annular hemi-gap junction vesicle that can then fuse with a single-membrane endosome [23,24,47,87]. However, the signals that would drive such a gap junction channel splitting shortly after internalization are not clear. It is possible that the small membrane separations devoid of gap junction channels (observed by ultrastructural studies in annular gap junctions [10,17,22]), likely 
corresponding to the "neck" of the plasma membrane invagination before forming the annular gap junction, are the sites for fusion with endosomes (shown schematically in Figure 2). In this case, the outer membrane of this small region could fuse with the singlemembrane endosome generating a larger vesicle (part endosome on one side, part gap junction plaque on the other side). The inner layer of the gap junction could then split away from the outer layer, for example based on increasing acidification as is typical for cargo/ cargo-receptor separation, forming an internal vesicle (complementing the inner hemi-gap junction plaque) that then can be degraded via, or resulting in the formation of multivesicular bodies, a vesicular structure known to proceed lysosomal fusion [88,89] (Figure 2, left bottom portion). Analysis of cells incubated in media containing fluorescently labeled wheat germ agglutinin (WGA), a plasma membrane impermeant lectin that binds sialic acid and $\mathrm{N}$-acetylglucosamine demonstrated that about $50 \%$ of annular gap junctions (probably the ones that were internalized during the WGA-labeling period) contained a punctum of fluorescently labeled WGA [22]. Sialic acid and N-acetylglucosamine are carbohydrate moieties that are common on the surface of glycosylated plasma membrane proteins. Since connexins are not glycosylated and are densely packed within gap junction plaques, these data lent support to the idea that the small membrane separation observed in annular gap junctions corresponds to non-junctional membranes where fusion with endosomes may take place.

\subsection{Autophagy}

Several recent studies in different tissues, primary cultured cells and cell lines have demonstrated that gap junctions are subject to constitutive and induced autophagy (Figure 2). Autophagosomes exhibit a highly characteristic, clearly recognizable double-membrane structure on ultra-thin sections, making conventional electron microscopy a highly reliable technique for the characterization of autophagosomes [36]. In all studies, cytoplasmic AGJ vesicles were detected inside phagophores by ultrastructural analyses (see Figure $1 \mathrm{E}-\mathrm{G}$ as examples). Also, all of these studies have shown co-localization of endogenously or exogenously expressed LC3 with several connexins including Cx26, Cx32, Cx43 and Cx50 under control conditions or after induction of autophagy and in the absence and/or the presence of lysosomal inhibitors [90-93], indicating the presence of these GJ components in autophagosomes. Additionally, expression of a conjugation-deficient LC3 prevented its colocalization with $\mathrm{Cx} 43$ annular gap junctions [91].

Inhibition of autophagy by pharmacological agents (e.g., wortmannin or bafilomycin A1) resulted in accumulation of annular gap junctions [91]. Treatment of serum-deprived COS-7 cells exogenously expressing Cx43 with the PI3K inhibitor, 3-methyladenine, decreased the degradation of the Triton X-100-insoluble fraction of Cx43 [90]. Genetic silencing of autophagy-associated genes (e.g., LC3, Atg6, LAMP-2 or p62) resulted in accumulation of annular gap junctions and reduced co-localization of LC3 with $\mathrm{Cx} 43$ [91]. Genetic deletion of Atg5 or siRNA-knockdown of Atg7 reduced the starvation-induced decrease in connexin levels $[90,93]$. The starvation-induced decrease in connexins was sensitive to lysosomal inhibitors [90,93], but not to proteasomal inhibitors [90]. 
In the heart, LC3-positive vesicles were observed in starved mice expressing GFP-LC3 [36]. Starvation also decreased Cx43 immuno-reactivity at appositional membranes and increased intracellular staining in mouse hearts [94]. In a canine model of heart failure, gap junctions became lateralized and appeared to be internalizing. In this model, double membranes that were suggested to be putative isolation membranes were detected in close association with internalized gap junctions [92]. Levels of LC3-II in whole heart homogenates and of $\mathrm{Cx} 43$ in lipid rafts were increased in failing, compared with normal heart [92]. In the liver, levels of Cx26, Cx32 and Cx43 were higher in the autophagosome subcellular fraction from starved compared with fed wild type mice [90]. Additionally, levels of $\mathrm{Cx} 43$ were increased in livers from macroautophagy-compromised compared to wild type mice [90].

The structural organization of annular gap junction vesicles representing cytoplasmically localized multi-protein complexes, that in addition are para-crystalline packed, renders autophagy as the most apparent annular gap junction degradation pathway. However, the level of constitutive and induced autophagy contributing to gap junction turnover may vary and depend on the cell type [90,93], and possibly also on the connexin subtype [90]. Bejarano et al. estimated that in transfected COS-7 cells, $\sim 20 \%$ of the gap junction plaque Cx43 (Triton X-100-insoluble fraction) was degraded by autophagy under normal conditions [90].

Based on results obtained by silencing expression of Eps15, Nedd4 or Atg7 and changes in their interaction with $\mathrm{Cx} 43$, Bejarano et al. have proposed a mechanism for the autophagic degradation of $\mathrm{Cx} 43$ at gap junction plaques: Nedd4-mediated ubiquitination of Cx43 in gap junction plaques recruits Eps15 to gap junctions, which would initiate their autophagydependent internalization and degradation [90] (see Figure 2, bottom right portion).

\section{Degradation of disease-linked mutant connexins}

Several disease-associated connexin mutants do not traffic properly and localize in compartments of the secretory pathway (e.g., endoplasmic reticulum [ER], endoplasmic reticulum Golgi intermediate compartment [ERGIC], and Golgi) $[95,96]$. Some of the Charcot-Marie Tooth disease (CMTX)-linked Cx32 mutants of this type are dislocated from the ER (after retrograde transport to the ER if they reach post-ER compartments) and are degraded by the proteasome [73]. One of these mutants, Cx32E208K, localizes to the ER and its ER-associated degradation is reduced by cellular stress before its dislocation from the ER, a phenomenon associated with decreased poly-ubiquitination of the mutant protein compared with that of proteasome-inhibitor stabilized mutant protein [97]. Proteasomal inhibition increased the levels of mutant $\mathrm{Cx} 32$ protein, but did not alter their cytoplasmic distribution [73]. In contrast, trafficking to the plasma membrane and function of an autosomal recessive cataract-linked Cx50 mutant, Cx50fs, which undergoes proteasomal degradation, were rescued by proteasomal inhibition [98]. These effects were independent of Akt protein kinase activity [98].

Some of the erythrokeratoderma variabilis-linked Cx31 mutants (expressed as eGFP fusion proteins) formed large aggregates in the cytoplasm that did not co-localize with proteins 
residing in the ER, Golgi or lysosomes. These mutants increased 20S core proteasome immunoreactivity, and co-localization between the proteasomal marker and the mutants was observed [99].

Some connexin mutants that do not traffic properly are not degraded by the proteasome. Chloroquine treatment of HeLa cells transfected with CMTX-associated Cx32 mutants that are retained in the Golgi led to intracellular accumulation of Cx32-positive granules that partially co-localized with a lysosomal-associated membrane protein [100]. Thus, at least some of the mutants may be routed directly to the lysosome for degradation resembling the by-pass pathway described by Qin et al. [72]. The cataract associated Cx50 mutant, Cx50P88S, forms ER-derived intracellular accumulations [101,102]. The Cx50P88S accumulations co-localized with markers of the autophagosome suggesting that these accumulations formed because of an overload of the autophagosomal capacity of the cells [93].

\section{Conclusions and perspectives}

It is likely that in vivo all the mechanisms described above participate in connexin, connexon, and gap junction degradation, and that the contribution of each of these pathways is modified depending on environmental conditions. Having multiple proteolytic pathways to control connexin levels, hemichannel function, and gap junctional intercellular communication would allow cells to compensate for a malfunctioning or compromised pathway, and to adapt to changing conditions.

Wild type connexins can be degraded by the proteasome, but ubiquitination of endoplasmic reticulum-retained connexins may not be an absolute requirement. Similarly, the molecular mechanisms triggering gap junction plaque internalization and degradation are still not well defined, but phosphorylation and ubiquitination emerge as likely events. Even less is known about hemichannel degradation.

Several questions remain to be answered regarding modification of connexins by ubiquitin. What are the types of ubiquitin chains modifying connexins? Do modifications by different ubiquitin chains or at different amino acid residues in the connexin polypeptide have different roles (degradation vs. intracellular trafficking)? Do they target connexins for degradation through different pathways? Are different E3 ubiquitin ligases responsible for ubiquitination at different amino acid residues in connexins in different subcellular compartments? Are there other modifications that affect the rate of connexin and gap junction degradation? It would appear plausible if $\mathrm{Cx} 43$ in gap junction plaques would become lysine63-polyubiquitinated, since Nedd4 is known to preferentially add lysine63polyubiquitin chains to target proteins [103], lysine63-polyubiquitinated target proteins are recognized by CLASPs, specifically Epsin1/2 and Eps15/Eps15R [48], and this type of ubiquitin modification can act as an internalization signal for clathrin-mediated endocytosis (CME) $[104,105]$. Yet, so far multiple mono-ubiquitination of $\mathrm{Cx} 43$ has been described and associated with the internalization of gap junctions. Future research will clearly be required to determine the potentially numerous types and functions of ubiquitinations that occur on 
connexins in different cellular locations (e.g. intracellular membranes versus plasma membranes).

Connexin phosphorylation can decrease intercellular communication by gating channels closed or by targeting gap junctions for internalization and subsequent degradation [26,37,39,106-108]. As shown for Cx43, phosphorylation and/or dephosphorylation events can lead to potentially significant conformational changes in the protein $[107,108]$. Such structural alterations may allow interaction of components of the endocytic machinery with connexins destined for internalization. The phosphorylation events crucial for triggering gap junction internalization and which of these events are cell-type specific remain to be determined.

Recycling of internalized connexins at the plasma membrane has been demonstrated [109]. It is unknown whether recycled connexins have lost their modifications or whether there is a hierarchy among the different connexin modifications that targets them definitely for degradation or allows them to be recycled to the plasma membrane. Future studies on these topics, the advanced state of research technology available today, and the increased interest in gap junction biology promise a better understanding of the diverse and multifaceted aspects of gap junction internalization and degradation.

\section{Acknowledgments}

We apologize to authors whose original works have not been cited due to space limitations. Work in the authors' laboratories is supported by grants from the National Institutes of Health, grant RO1-GM55725-13 (to M.M.F.), and RO1-EY08368 (to Eric C. Beyer).

\section{References}

1. Beardslee MA, Laing JG, Beyer EC, Saffitz JE. Rapid turnover of connexin43 in the adult rat heart. Circ Res. 1998; 83:629-35. [PubMed: 9742058]

2. Berthoud VM, Minogue PJ, Laing JG, Beyer EC. Pathways for degradation of connexins and gap junctions. Cardiovasc Res. 2004; 62:256-67. [PubMed: 15094346]

3. Falk MM, Baker SM, Gumpert AM, Segretain D, Buckheit RW 3rd. Gap junction turnover is achieved by the internalization of small endocytic double-membrane vesicles. Mol Biol Cell. 2009; 20:3342-52. [PubMed: 19458184]

4. Fallon RF, Goodenough DA. Five-hour half-life of mouse liver gap-junction protein. J Cell Biol. 1981; 90:521-6. [PubMed: 7287816]

5. Gaietta G, et al. Multicolor and electron microscopic imaging of connexin trafficking. Science. 2002; 296:503-7. [PubMed: 11964472]

6. Bjorkman N. A study of the ultrastructure of the granulosa cells of the rat ovary. Acta Anat (Basel). 1962; 51:125-47. [PubMed: 13971315]

7. Ginzberg RD, Gilula NB. Modulation of cell junctions during differentiation of the chicken otocyst sensory epithelium. Developmental Biology. 1979; 68:110-29. [PubMed: 437313]

8. Larsen WJ, Tung HN, Murray SA, Swenson CA. Evidence for the participation of actin microfilaments and bristle coats in the internalization of gap junction membrane. J Cell Biol. 1979; 83:576-87. [PubMed: 574870]

9. Leach DH, Oliphant LW. Degradation of annular gap junctions of the equine hoof wall. Acta Anat (Basel). 1984; 120:214-9. [PubMed: 6516782]

10. Mazet F, Wittenberg BA, Spray DC. Fate of intercellular junctions in isolated adult rat cardiac cells. Circ Res. 1985; 56:195-204. [PubMed: 3971501] 
11. Pfeifer U. Autophagic sequestration of internalized gap junctions in rat liver. Eur J Cell Biol. 1980; 21:244-6. [PubMed: 7449766]

12. Severs NJ, Shovel KS, Slade AM, Powell T, Twist VW, Green CR. Fate of gap junctions in isolated adult mammalian cardiomyocytes. Circulation Research. 1989; 65:22-42. [PubMed: 2736737]

13. Hayward AF, Kent AP. Gap junctions in the epidermis of fetal rats studied by transmission electron microscopy. J Ultrastruct Res. 1983; 84:182-93. [PubMed: 6195354]

14. Sasaki T, Garant PR. Fate of annular gap junctions in the papillary cells of the enamel organ in the rat incisor. Cell Tissue Res. 1986; 246:523-30. [PubMed: 3024840]

15. Fong JT, Kells RM, Falk MM. Two tyrosine-based sorting signals in the Cx43 C-terminus cooperate to mediate gap junction endocytosis. Mol Biol Cell. 2013; 24:2834-48. [PubMed: 23885125]

16. Jordan K, Chodock R, Hand AR, Laird DW. The origin of annular junctions: a mechanism of gap junction internalization. J Cell Sci. 2001; 114:763-73. [PubMed: 11171382]

17. Piehl M, Lehmann C, Gumpert A, Denizot JP, Segretain D, Falk MM. Internalization of large double-membrane intercellular vesicles by a clathrin-dependent endocytic process. Mol Biol Cell. 2007; 18:337-47. [PubMed: 17108328]

18. Schlingmann B, Schadzek P, Hemmerling F, Schaarschmidt F, Heisterkamp A, Ngezahayo A. The role of the C-terminus in functional expression and internalization of rat connexin46 ( $\mathrm{rCx} 46)$. J Bioenerg Biomembr. 2013; 45:59-70. [PubMed: 23065326]

19. Ghoshroy S, Goodenough DA, Sosinsky GE. Preparation, characterization, and structure of half gap junctional layers split with urea and EGTA. Journal of Membrane Biology. 1995; 146:15-28. [PubMed: 7563034]

20. Goodenough DA, Gilula NB. The splitting of hepatocyte gap junctions and zonulae occludentes with hypertonic disaccharides. Journal of Cell Biology. 1974; 61:575-90. [PubMed: 4836384]

21. Nickel BM, DeFranco BH, Gay VL, Murray SA. Clathrin and Cx43 gap junction plaque endoexocytosis. Biochem Biophys Res Commun. 2008; 374:679-82. [PubMed: 18675253]

22. Falk MM, Fong JT, Kells RM, O'Laughlin MC, Kowal TJ, Thevenin AF. Degradation of Endocytosed Gap Junctions by Autophagosomal and Endo-/lysosomal Pathways: A Perspective. J Membr Biol. 2012; 245:465-476. [PubMed: 22825714]

23. Kjenseth A, Fykerud T, Rivedal E, Leithe E. Regulation of gap junction intercellular communication by the ubiquitin system. Cell Signal. 2010; 22:1267-73. [PubMed: 20206687]

24. Leithe E, Sirnes S, Fykerud T, Kjenseth A, Rivedal E. Endocytosis and post-endocytic sorting of connexins. Biochim Biophys Acta. 2012; 18:1870-1879. [PubMed: 21996040]

25. Su V, Lau AF. Ubiquitination, intracellular trafficking, and degradation of connexins. Arch Biochem Biophys. 2012; 524:16-22. [PubMed: 22239989]

26. Thévenin AF, Kowal TJ, Fong JT, Kells RM, Fisher CG, Falk MM. Proteins and Mechanisms Regulating Gap Junction Assembly. Internalization and Degradation Physiology. 2013; 28:93116.

27. Voges D, Zwickl P, Baumeister W. The 26S proteasome: a molecular machine designed for controlled proteolysis. Annu Rev Biochem. 1999; 68:1015-68. [PubMed: 10872471]

28. Goldberg AL. Development of proteasome inhibitors as research tools and cancer drugs. J Cell Biol. 2012; 199:583-8. [PubMed: 23148232]

29. Moore BS, Eustaquio AS, McGlinchey RP. Advances in and applications of proteasome inhibitors. Curr Opin Chem Biol. 2008; 12:434-40. [PubMed: 18656549]

30. Kravtsova-Ivantsiv Y, Ciechanover A. Non-canonical ubiquitin-based signals for proteasomal degradation. J Cell Sci. 2012; 125:539-48. [PubMed: 22389393]

31. Bjorkoy G, Lamark T, Brech A, Outzen H, Perander M, Overvatn A, Stenmark H, Johansen T. p62/SQSTM1 forms protein aggregates degraded by autophagy and has a protective effect on huntingtin-induced cell death. J Cell Biol. 2005; 171:603-14. [PubMed: 16286508]

32. Hung SY, Huang WP, Liou HC, Fu WM. Autophagy protects neuron from Abeta-induced cytotoxicity. Autophagy. 2009; 5:502-10. [PubMed: 19270530] 
33. Pohl C, Jentsch S. Midbody ring disposal by autophagy is a post-abscission event of cytokinesis. Nat Cell Biol. 2009; 11:65-70. [PubMed: 19079246]

34. Ravikumar B, Imarisio S, Sarkar S, O'Kane CJ, Rubinsztein DC. Rab5 modulates aggregation and toxicity of mutant huntingtin through macroautophagy in cell and fly models of Huntington disease. J Cell Sci. 2008; 121:1649-60. [PubMed: 18430781]

35. Kabeya Y, et al. LC3, a mammalian homologue of yeast Apg8p, is localized in autophagosome membranes after processing. EMBO J. 2000; 19:5720-8. [PubMed: 11060023]

36. Mizushima N. Methods for monitoring autophagy. Int J Biochem Cell Biol. 2004; 36:2491-502. [PubMed: 15325587]

37. Axelsen LN, Calloe K, Holstein-Rathlou NH, Nielsen MS. Managing the complexity of communication: regulation of gap junctions by post-translational modification. Front Pharmacol. 2013; 4:1-18. [PubMed: 23346057]

38. Johnstone SR, Billaud M, Lohman AW, Taddeo EP, Isakson BE. Posttranslational Modifications in Connexins and Pannexins. J Membr Biol. 2012; 245:319-332. [PubMed: 22739962]

39. Laird DW. Connexin phosphorylation as a regulatory event linked to gap junction internalization and degradation. Biochim Biophys Acta. 2005; 1711:172-82. [PubMed: 15955302]

40. Laing JG, Beyer EC. The gap junction protein connexin43 is degraded via the ubiquitin proteasome pathway. Journal of Biological Chemistry. 1995; 270:26399-403. [PubMed: 7592854]

41. Yin X, Liu J, Jiang JX. Lens fiber connexin turnover and caspase-3-mediated cleavage are regulated alternately by phosphorylation. Cell Commun Adhes. 2008; 15:1-11. [PubMed: 18649174]

42. Girao H, Catarino S, Pereira P. Eps 15 interacts with ubiquitinated Cx43 and mediates its internalization. Exp Cell Res. 2009; 315:3587-97. [PubMed: 19835873]

43. Leithe E, Rivedal E. Epidermal growth factor regulates ubiquitination, internalization and proteasome-dependent degradation of connexin43. J Cell Sci. 2004; 117:1211-20. [PubMed: 14970263]

44. Chen VC, Kristensen AR, Foster LJ, Naus C. The Association of Cx43 with E3 Ubiquitin Ligase TRIM21 Reveals a Mechanism for Gap Junction Phosphodegron Control. J Proteome Res. 2012

45. Fykerud TA, et al. Smad ubiquitination regulatory factor-2 controls gap junction intercellular communication by modulating endocytosis and degradation of connexin43. J Cell Sci. 2012; 125:3966-76. [PubMed: 22623726]

46. Leykauf K, Salek M, Bomke J, Frech M, Lehmann WD, Durst M, Alonso A. Ubiquitin protein ligase Nedd4 binds to connexin43 by a phosphorylation-modulated process. J Cell Sci. 2006; 119:3634-42. [PubMed: 16931598]

47. Leithe E, Kjenseth A, Sirnes S, Stenmark H, Brech A, Rivedal E. Ubiquitylation of the gap junction protein connexin-43 signals its trafficking from early endosomes to lysosomes in a process mediated by Hrs and Tsg101. J Cell Sci. 2009; 122:3883-93. [PubMed: 19808888]

48. Traub LM, Lukacs GL. Decoding ubiquitin sorting signals for clathrin-dependent endocytosis by CLASPs. J Cell Sci. 2007; 120:543-53. [PubMed: 17287393]

49. Ohzono C, Etoh S, Matsumoto M, Nakayama KI, Hirota Y, Tanaka Y, Fujita H. Nedd4-interacting protein 2, a short half-life membrane protein degraded in lysosomes, negatively controls downregulation of connexin43. Biol Pharm Bull. 2010; 33:951-7. [PubMed: 20522958]

50. Leithe E, Rivedal E. Ubiquitination and down-regulation of gap junction protein connexin-43 in response to 12-O-tetradecanoylphorbol 13-acetate treatment. J Biol Chem. 2004; 279:50089-96. [PubMed: 15371442]

51. Postma FR, Hengeveld T, Alblas J, Giepmans BN, Zondag GC, Jalink K, Moolenaar WH. Acute loss of cell-cell communication caused by $\mathrm{G}$ protein-coupled receptors: a critical role for c-Src. J Cell Biol. 1998; 140:1199-209. [PubMed: 9490732]

52. Wagner SA, Beli P, Weinert BT, Nielsen ML, Cox J, Mann M, Choudhary C. A proteome-wide, quantitative survey of in vivo ubiquitylation sites reveals widespread regulatory roles. Mol Cell Proteomics. 2011; 10:1-13. 1074/mcp.M111 013284.

53. Wagner SA, et al. Proteomic analyses reveal divergent ubiquitylation site patterns in murine tissues. Mol Cell Proteomics. 2012; 11:1578-85. [PubMed: 22790023] 
54. Gilleron J, Carette D, Fiorini C, Dompierre J, Macia E, Denizot JP, Segretain D, Pointis G. The large GTPase dynamin2: a new player in connexin 43 gap junction endocytosis, recycling and degradation. Int J Biochem Cell Biol. 2011; 43:1208-17. [PubMed: 21554976]

55. Gumpert AM, Varco JS, Baker SM, Piehl M, Falk MM. Double-membrane gap junction internalization requires the clathrin-mediated endocytic machinery. FEBS Letters. 2008; 582:2887-2892. [PubMed: 18656476]

56. Huang XD, Horackova M, Pressler ML. Changes in the expression and distribution of connexin 43 in isolated cultured adult guinea pig cardiomyocytes. Exp Cell Res. 1996; 228:254-61. [PubMed: 8912718]

57. Naus CC, Hearn S, Zhu D, Nicholson BJ, Shivers RR. Ultrastructural analysis of gap junctions in C6 glioma cells transfected with connexin43 cDNA. Exp Cell Res. 1993; 206:72-84. [PubMed: 8387023]

58. Nickel B, Boller M, Schneider K, Shakespeare T, Gay V, Murray SA. Visualizing the effect of dynamin inhibition on annular gap vesicle formation and fission. J Cell Sci. 2013; 126:2607-16. [PubMed: 23591819]

59. Wayakanon P, Bhattacharjee R, Nakahama K, Morita I. The role of the Cx43 C-terminus in GJ plaque formation and internalization. Biochem Biophys Res Commun. 2012; 420:456-61. [PubMed: 22430144]

60. Cocucci E, Aguet F, Boulant S, Kirchhausen T. The first five seconds in the life of a clathrincoated pit. Cell. 2012; 150:495-507. [PubMed: 22863004]

61. Zoncu R, et al. Loss of endocytic clathrin-coated pits upon acute depletion of phosphatidylinositol 4,5-bisphosphate. Proc Natl Acad Sci U S A. 2007; 104:3793-8. [PubMed: 17360432]

62. Chen B, Dores MR, Grimsey N, Canto I, Barker BL, Trejo J. Adaptor protein complex-2 (AP-2) and epsin-1 mediate protease-activated receptor-1 internalization via phosphorylation- and ubiquitination-dependent sorting signals. J Biol Chem. 2011; 286:40760-70. [PubMed: 21965661]

63. Barker RJ, Price RL, Gourdie RG. Increased association of ZO-1 with connexin43 during remodeling of cardiac gap junctions. Circ Res. 2002; 90:317-24. [PubMed: 11861421]

64. Baker SM, Kim N, Gumpert AM, Segretain D, Falk MM. Acute internalization of gap junctions in vascular endothelial cells in response to inflammatory mediator-induced G-protein coupled receptor activation. FEBS Lett. 2008; 582:4039-46. [PubMed: 18992245]

65. Gilleron J, Fiorini C, Carette D, Avondet C, Falk MM, Segretain D, Pointis G. Molecular reorganization of $\mathrm{Cx} 43, \mathrm{Zo}-1$ and Src complexes during the endocytosis of gap junction plaques in response to a non-genomic carcinogen. J Cell Sci. 2008; 121:4069-78. [PubMed: 19033388]

66. Komander D. The emerging complexity of protein ubiquitination. Biochem Soc Trans. 2009; 37:937-53. [PubMed: 19754430]

67. Komander D, Rape M. The ubiquitin code. Annu Rev Biochem. 2012; 81:203-29. [PubMed: 22524316]

68. Pankiv S, et al. p62/SQSTM1 binds directly to Atg8/LC3 to facilitate degradation of ubiquitinated protein aggregates by autophagy. J Biol Chem. 2007; 282:24131-45. [PubMed: 17580304]

69. Laing JG, Tadros PN, Green K, Saffitz JE, Beyer EC. Proteolysis of connexin43-containing gap junctions in normal and heat-stressed cardiac myocytes. Cardiovasc Res. 1998; 38:711-8. [PubMed: 9747439]

70. Laing JG, Tadros PN, Westphale EM, Beyer EC. Degradation of connexin43 gap junctions involves both the proteasome and the lysosome. Exp Cell Res. 1997; 236:482-92. [PubMed: 9367633]

71. Musil LS, Le AC, VanSlyke JK, Roberts LM. Regulation of connexin degradation as a mechanism to increase gap junction assembly and function. J Biol Chem. 2000; 275:25207-15. [PubMed: 10940315]

72. Qin H, Shao Q, Igdoura SA, Alaoui-Jamali MA, Laird DW. Lysosomal and proteasomal degradation play distinct roles in the life cycle of $\mathrm{Cx} 43$ in gap junctional intercellular communication-deficient and -competent breast tumor cells. J Biol Chem. 2003; 278:30005-14. [PubMed: 12767974] 
73. VanSlyke JK, Deschenes SM, Musil LS. Intracellular transport, assembly, and degradation of wildtype and disease-linked mutant gap junction proteins. Mol Biol Cell. 2000; 11:1933-46. [PubMed: 10848620]

74. VanSlyke JK, Musil LS. Dislocation and degradation from the ER are regulated by cytosolic stress. J Cell Biol. 2002; 157:381-94. [PubMed: 11980915]

75. Li X, Su V, Kurata WE, Jin C, Lau AF. A novel connexin43-interacting protein, CIP75, which belongs to the UbL-UBA protein family, regulates the turnover of connexin43. J Biol Chem. 2008; 283:5748-59. [PubMed: 18079109]

76. Su V, Hoang C, Geerts D, Lau AF. The connexin43-interacting protein of $75 \mathrm{kDa}$ (CIP75) mediates the endoplasmic reticulum dislocation of connexin43. Biochem J. 2013 (Epub ahead of print).

77. Su V, Nakagawa R, Koval M, Lau AF. Ubiquitin-independent proteasomal degradation of endoplasmic reticulum-localized connexin43 mediated by CIP75. J Biol Chem. 2010; 285:4097990. [PubMed: 20940304]

78. Su V, Cochrane K, Lau AF. Degradation of connexins through the proteasomal, endolysosomal and phagolysosomal pathways. J Membr Biol. 2012; 245:389-400. [PubMed: 22772442]

79. Koval M. Pathways and control of connexin oligomerization. Trends Cell Biol. 2006; 16:159-66. [PubMed: 16490353]

80. Larson DM, Christensen TG, Sagar GD, Beyer EC. TGF-beta1 induces an accumulation of connexin43 in a lysosomal compartment in endothelial cells. Endothelium. 2001; 8:255-60. [PubMed: 11824477]

81. Rutz ML, Hulser DF. Supramolecular dynamics of gap junctions. Eur J Cell Biol. 2001; 80:20-30. [PubMed: 11211932]

82. Girao H, Pereira P. The proteasome regulates the interaction between Cx43 and ZO-1. J Cell Biochem. 2007; 102:719-28. [PubMed: 17541973]

83. Dunn CA, Su V, Lau AF, Lampe PD. Activation of Akt, not connexin 43 protein ubiquitination, regulates gap junction stability. J Biol Chem. 2012; 287:2600-7. [PubMed: 22139843]

84. Gregory WA, Bennett MV. Gap junctions in goldfish preoptic ependyma: regional variation in cellular differentiation. Brain Res. 1988; 470:205-16. [PubMed: 3219581]

85. Murray SA, Larsen WJ, Trout J, Donta ST. Gap junction assembly and endocytosis correlated with patterns of growth in a cultured adrenocortical tumor cell (SW-13). Cancer Res. 1981; 41:406374. [PubMed: 7285014]

86. Vaughan DK, Lasater EM. Renewal of electrotonic synapses in teleost retinal horizontal cells. J Comp Neurol. 1990; 299:364-74. [PubMed: 2229483]

87. Kjenseth A, et al. The gap junction channel protein connexin43 is covalently modified and regulated by SUMOylation. J Biol Chem. 2012; 287:15851-15861. [PubMed: 22411987]

88. Babst M. MVB vesicle formation: ESCRT-dependent, ESCRT-independent and everything in between. Curr Opin Cell Biol. 2011; 23:452-7. [PubMed: 21570275]

89. Hanson PI, Cashikar A. Multivesicular body morphogenesis. Annu Rev Cell Dev Biol. 2012; 28:337-62. [PubMed: 22831642]

90. Bejarano E, Girao H, Yuste A, Patel B, Marques C, Spray DC, Pereira P, Cuervo AM. Autophagy modulates dynamics of connexins at the plasma membrane in a ubiquitin-dependent manner. Mol Biol Cell. 2012; 23:2156-69. [PubMed: 22496425]

91. Fong JT, Kells RM, Gumpert AM, Marzillier JY, Davidson MW, Falk MM. Internalized gap junctions are degraded by autophagy. Autophagy. 2012; 8:794-811. [PubMed: 22635056]

92. Hesketh GG, et al. Ultrastructure and regulation of lateralized connexin 43 in the failing heart. Circ Res. 2010; 106:1153-63. [PubMed: 20167932]

93. Lichtenstein A, Minogue PJ, Beyer EC, Berthoud VM. Autophagy: a pathway that contributes to connexin degradation. J Cell Sci. 2011; 124:910-20. [PubMed: 21378309]

94. McLachlan CS, Almsherqi ZA, Mossop P, Suzuki J, Leong ST, Deng Y. Down regulation of immuno-detectable cardiac connexin-43 in BALB/c mice following acute fasting. Int J Cardiol. 2009; 136:99-102. [PubMed: 18606469]

95. Laird DW. Life cycle of connexins in health and disease. Biochem J. 2006; 394:527-43. [PubMed: 16492141] 
96. Pfenniger A, Wohlwend A, Kwak BR. Mutations in connexin genes and disease. Eur J Clin Invest. 2011; 41:103-16. [PubMed: 20840374]

97. Kelly SM, Vanslyke JK, Musil LS. Regulation of ubiquitin-proteasome system mediated degradation by cytosolic stress. Mol Biol Cell. 2007; 18:4279-91. [PubMed: 17699585]

98. Minogue PJ, Beyer EC, Berthoud VM. A connexin50 mutant, CX50fs, that causes cataracts is unstable, but is rescued by a proteasomal inhibitor. J Biol Chem. 2013; 288:20427-34. [PubMed: 23720739]

99. Tattersall D, Scott CA, Gray C, Zicha D, Kelsell DP. EKV mutant connexin 31 associated cell death is mediated by ER stress. Hum Mol Genet. 2009; 18:4734-45. [PubMed: 19755382]

100. Kleopa KA, Yum SW, Scherer SS. Cellular mechanisms of connexin32 mutations associated with CNS manifestations. J Neurosci Res. 2002; 68:522-34. [PubMed: 12111842]

101. Berthoud VM, Minogue PJ, Guo J, Williamson EK, Xu X, Ebihara L, Beyer EC. Loss of function and impaired degradation of a cataract-associated mutant connexin50. Eur J Cell Biol. 2003; 82:209-21. [PubMed: 12800976]

102. Lichtenstein A, Gaietta GM, Deerinck TJ, Crum J, Sosinsky GE, Beyer EC, Berthoud VM. The cytoplasmic accumulations of the cataract-associated mutant, Connexin50P88S, are long-lived and form in the endoplasmic reticulum. Exp Eye Res. 2009; 88:600-9. [PubMed: 19073179]

103. Kim HT, Kim KP, Lledias F, Kisselev AF, Scaglione KM, Skowyra D, Gygi SP, Goldberg AL. Certain pairs of ubiquitin-conjugating enzymes (E2s) and ubiquitin-protein ligases (E3s) synthesize nondegradable forked ubiquitin chains containing all possible isopeptide linkages. J Biol Chem. 2007; 282:17375-86. [PubMed: 17426036]

104. Belouzard S, Rouille Y. Ubiquitylation of leptin receptor OB-Ra regulates its clathrin-mediated endocytosis. Embo J. 2006; 25:932-42. [PubMed: 16482222]

105. Geetha T, Jiang J, Wooten MW. Lysine 63 polyubiquitination of the nerve growth factor receptor TrkA directs internalization and signaling. Mol Cell. 2005; 20:301-12. [PubMed: 16246731]

106. Solan JL, Lampe PD. Key connexin 43 phosphorylation events regulate the gap junction life cycle. J Membr Biol. 2007; 217:35-41. [PubMed: 17629739]

107. Solan JL, Lampe PD. Connexin43 phosphorylation: structural changes and biological effects. Biochem J. 2009; 419:261-72. [PubMed: 19309313]

108. Solan JL, Marquez-Rosado L, Sorgen PL, Thornton PJ, Gafken PR, Lampe PD. Phosphorylation at $\mathrm{S} 365$ is a gatekeeper event that changes the structure of $\mathrm{Cx} 43$ and prevents down-regulation by PKC. J Cell Biol. 2007; 179:1301-9. [PubMed: 18086922]

109. VanSlyke JK, Musil LS. Cytosolic stress reduces degradation of connexin43 internalized from the cell surface and enhances gap junction formation and function. Mol Biol Cell. 2005; 16:5247-57. [PubMed: 16135529] 


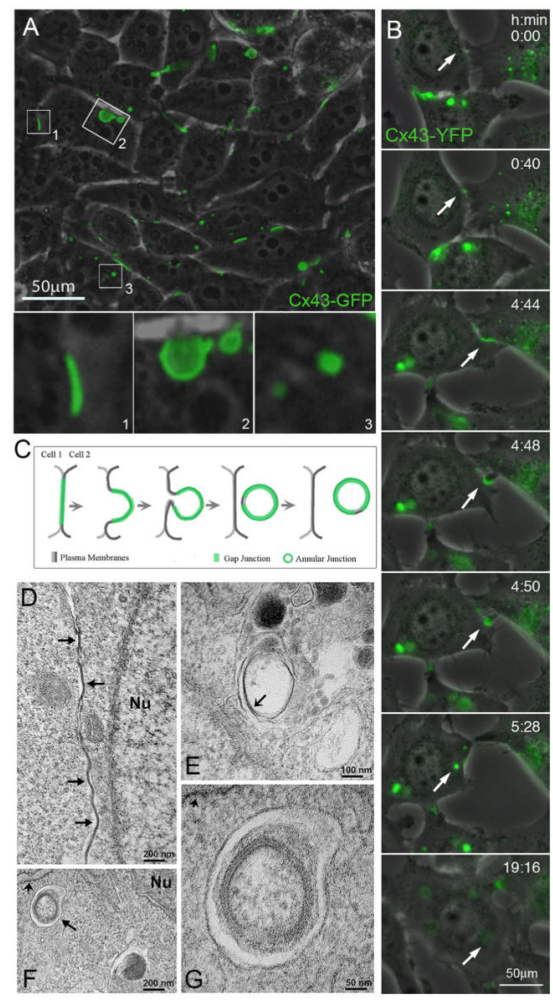

\section{Figure 1.}

Internalization of gap junction plaques. (A) Combined phase-contrast and fluorescence images of HeLa cells transfected with Cx43-GFP reveal efficient expression and assembly of gap junctions at appositional membranes of transfected cells (visible as green fluorescent lines and puncta such as the one shown in insert (1). Over time, gap junction plaques invaginate into the cytoplasm of one of the two cells (insert 2), detach from the plasma membrane and form endocytosed cytoplasmic annular gap junctions or connexosomes (insert 3). (B) Selected still-images of a time-lapse recording of stably transfected Cx43YFP expressing HeLa cells showing the formation of a gap junction, its internalization into the cytoplasm of one of the adjacent cells, and subsequent degradation of the generated annular gap junction, indicated by the loss of its fluorescence (marked with arrows). (C) Schematic representation depicting the progressive stages of gap junction internalization shown in A and B. (D) Electron micrograph showing GJs (arrows) at the appositional membranes of mouse embryonic fibroblasts. (E) Electron micrograph showing an internalized GJ structure within a membrane-surrounded compartment, which probably corresponds to a secondary lysosome or autolysosome. Note that the pentalaminar pattern characteristic of GJs is being lost (arrow) in the internalized structure, probably because it is undergoing degradation. (F) Electron micrograph obtained from mouse embryonic fibroblasts starved by incubation in Hank's balanced salt solution for 1 hour showing a double membrane structure, probably an autophagosome (arrow) that encloses an internalized GJ in close proximity to rough endoplasmic reticulum (short arrow). (G) Electron micrograph showing the internalized GJ enclosed within the autophagosome at higher magnification; the rough endoplasmic reticulum membrane is indicated by the short 
arrow. $\mathrm{Nu}$ : nucleus (A-C reproduced with permission from Landes Bioscience from ref. [91], D-G reproduced with permission from The Company of Biologists from ref. [93]). 


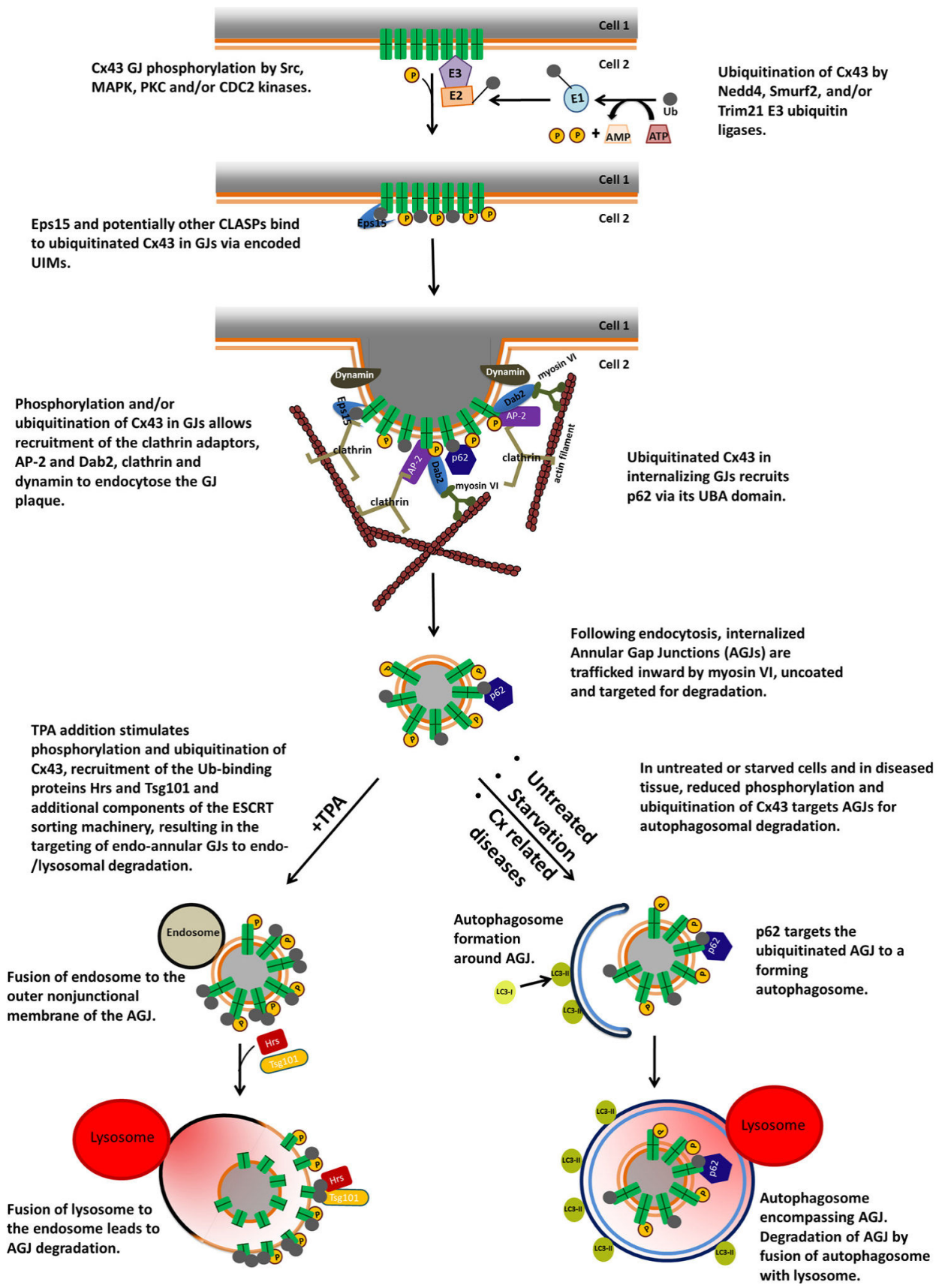

Figure 2.

Schematic representation of the signals participating in the proposed steps that lead to gap junction internalization, formation of annular gap junctions in the cytoplasm of the acceptor cell, and annular gap junction degradation through the phago-/lysosomal or the endo-/ lysosomal pathway based on studies published in the literature. (Abbreviations are: AGJ, annular gap junction; CLASPs, clathrin-coat-associated proteins; ESCRT, endosomal sorting complexes required for transport; GJ, gap junction; UBA, ubiquitin-associated domain; UIMs, ubiquitin-interacting motifs.) 